\title{
WHY SHOULD YOU BE DCP OF THE MONTH?
}

BDJ Team, in collaboration with the

Oral Health Foundation, is running a

I competition to showcase one dental care

I professional (DCP) each month both on

I the BDJ Team website and on the BDJ

I Team Facebook page (www.facebook.com/ bdjteam).

The July winner of DCP of the month will win instant fame (!) and a Little Bear demonstration puppet (pictured): the ideal tool for teaching younger patients good oral hygiene habits.

To be in with a chance of winning and I becoming DCP of the Month, just email us your name, job title, workplace, age, and town, and tell us why you should be

I DCP of the Month. Perhaps you have just

I completed a qualification or postgraduate I certificate, raised money for charity, organised a practice open day or special campaign for patients, gone into the community to educate people about oral health, or anything else you would like to tell BDJ Team readers and the dental community about.

Email bdjteam@nature.com by 30 May 2016. All entries must include a photo. ENTER TODAY TO BE IN WITH A CHANCE OF WINNING!

The Little Bear and a range of other demonstration products, models and downloads can be purchased from the Oral Health Foundation shop at https://www. educatingsmiles.org/.

Entry to the competition indicates that you are happy for your details and photograph to be used on the BDJ Team website, Facebook page and Twitter account (@Editorkate2).

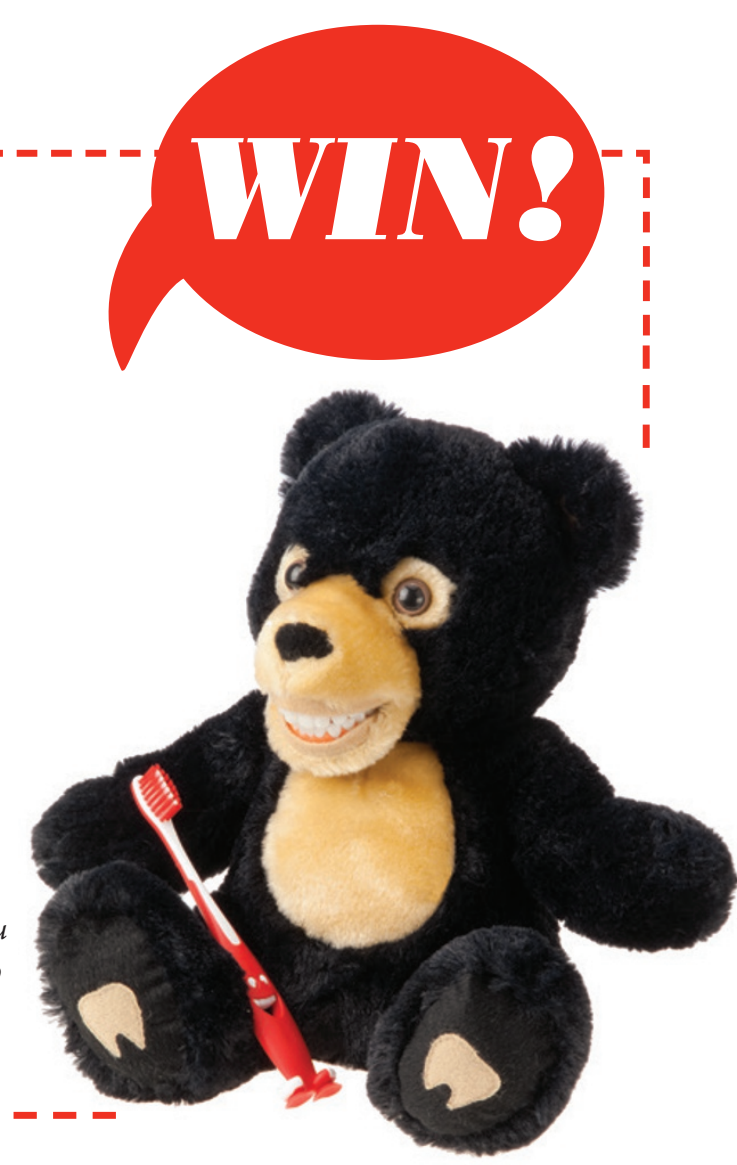

about the importance of good dental hygiene and other preventive measures.

'When we consider the current financial restraints within the NHS - and the seemingly unstoppable increase in chronic conditions such as diabetes - the role of dentistry has never been so important in an overall health care. The Government should consider funding these diabetes tests as an investment in the future health of a nation because, with regular screening, and education about preventive measures we can draw attention to this disease and keep the associated health risks at bay.'

This year, Philip Preshaw, professor of periodontology and consultant in restorative dentistry at Newcastle University, is the keynote speaker at the BADT's annual conference - From Cradle to Grey: Developing 21st century strategies for age-related oral care - taking place in Manchester on 23 and 24 September.

He will be addressing the clinical challenges presented by diabetic patients, will look at how the disease increases the risk for periodontitis and will offer an insight into the links between periodontal disease, diabetes and heart disease.

For more information, visit www.badt. org.uk.

For more on World Health Day, visit http://www.who.int/campaigns/worldhealth-day/2016/en/. 